\title{
Formação de professores da educação do campo: limites e possibilidades
}

\author{
Training of field education teachers: limits and potentialities \\ Sandra Madalena Valentim de Souza \\ Andrea Brandão Locatelli
}

\begin{abstract}
Resumo: O presente estudo, é resultado de uma pesquisa bibliográfica realizada no contexto de uma investigação que pretende compreender a educação do campo por meio de sua contextualização histórica, sua expansão e rupturas, os saberes dos professores da educação do campo a luz das contribuições dos estudos de Maurice Tardif e Clermont Gauthier a respeito dos saberes docentes dos professores. Apresentamos a relação entre si e os pontos de convergência das teorias apresentadas. E por fim, a conceituação do Tema Gerador e o processo de constituição dos temas geradores adotado pelas Escolas que trabalham com a Pedagogia da Alternância na região Norte do Estado do Espírito Santo. Em síntese, apresentou-se a Educação do Campo e seu contexto tempos/espaços baseado na Pedagogia da Alternância que encontra-se na formação de professores a aplicabilidade de sua proposta pedagógica e metodológica, reconhecendo os saberes dos professores e o seu papel como interlocutor no processo de investigação, limites e possibilidades acerca dos temas geradores. Observou se o processo de constituição dos temas geradores amplia ou limita a formação dos sujeitos. Concluiu que em partes o processo amplia no sentido da proposta pedagógica da Pedagogia da Alternância que se assemelha a proposta da Educação Popular, por outro lado, limita no processo de aprofundamento da definição dos temas, observou que não há participação dos sujeitos na totalidade, haja visto, que os temas são em sua maioria iguais a todas a escolas, porém, são espaços diferentes, tempos diferentes e sujeitos com culturas diferentes.
\end{abstract}

Palavras-Chave: Formação de Professores. Educação do Campo. Saberes Docentes. Temas Geradores.

Abstract: The present study is the result of a bibliographic research carried out in the context of an investigation that aims to understand rural education through its historical context, its expansion and ruptures, the knowledge of rural education teachers in the light of the contributions of studies by Maurice Tardif and Clermont Gauthier regarding teachers' teaching knowledge. We present the relationship between themselves and the points of convergence of the theories presented. And finally, the conceptualization of the generator theme and the process of constitution of the generator themes adopted by Schools that work with Pedagogy of Alternation in the Northern region of the State of Espírito Santo. In summary, the Education of the Field and its context of times / spaces was presented based on Pedagogy of Alternation, which is found in the training of teachers the applicability of their pedagogical and methodological proposal, recognizing the knowledge of teachers and their role as interlocutor in the research process, limits and possibilities regarding the generating themes. It was observed whether the process of constitution of the generating themes expands or limits the formation of the subjects. He concluded that in parts the process expands towards the pedagogical proposal of Pedagogy of Alternation, which resembles the proposal of Popular Education, on the other hand, it limits the process of deepening the definition of themes, he observed that there is no participation of the subjects in full, there is since the themes are mostly the same as all schools, however, they are different spaces, different times and subjects with different cultures. 
Keywords: Teacher Education. Rural Education. Teaching Knowledge. Generating themes.

\section{Introdução}

No que concerne a Educação do Campo no Brasil e no Estado do Espírito Santo, dentre outros fatores, destaca-se a contextualização histórica, sua expansão e rupturas, assim como, a formação de professores e os saberes docentes. Neste sentido, far-se-á neste estudo um recorte da região Norte do Estado do Espírito Santo onde concentra o maior número de escolas do campo.

Como elemento norteador das atividades pedagógicas que emergem do diagnóstico, de motivações e interesses das pessoas e da realidade de abrangência da escola, propusemos para o estudo conceituar os Temas Geradores e seu processo de constituição adotado pelas Escolas Multisseriadas do município de São Mateus e a escolas que trabalham com a Pedagogia da Alternância.

Para tanto, consideramos importante discorrer inicialmente sobre 0 processo de luta pela formação de professores ocorrido no Brasil a partir do final da década de 1970. De acordo com Alves (2001), os processos relacionados ao movimento pela democratização do país, no final da década de 1970 do século $X X$, foram realizados por lutas que visavam mudanças pela Educação. Enquanto isso nesse momento a França criava por todo o seu território o Institutos Superior de Educação, em 1982, o Ministério da Educação (MEC) realizava em Brasília, um colóquio ao qual comparecem franceses e brasileiros, em uma tentativa de tencionar que esse poderia ser o caminho o qual o Brasil podia seguir.

Nesse Encontro Nacional, Alves (2001), considera que contrariando as tentativas de condução oficial, respaldados por ampla discussão nacional, os representantes de todos os estados e do Distrito Federal, das diversas universidades e secretarias de educação produziram um documento que analisava e propôs mudanças possíveis para todos os níveis do sistema de ensino, entendendo que devem ser pensados articuladamente.

Alves (2001), ainda destaca que esse documento nunca foi incorporado como orientador pelo MEC, mas, em contrapartida, foi o documento inicial para as ações da Comissão Nacional de Reformulação dos Cursos de Formação do 
Educador, que teve como sua primeira presidente Márcia Ângela Aguiar e continuou a sê-lo quando a ANFOPE foi criada, tendo Luiz Carlos de Freitas como seu primeiro presidente (1990).

Em suma, esse documento de 1983, quando pensado a formação docente, foi criada a ideia de possibilitar a existência de uma base comum nacional, para o qual é explicitada uma metodologia de trabalho. Acompanhando experiências que vinham sendo realizadas em poucas universidades, a exemplo, a Universidade Federal de Goiás (UFG) que foi uma delas e a ela foram dedicados diversos debates. Naquele momento, indicava que essas instituições deveriam propor currículos diversos, em acordo com seus docentes e discentes e com ampla relação com as questões regionais.

Nesse movimento de luta e mobilização a favor da educação diversos atores corroboraram como protagonista. Professores, pesquisadores foram atores fundamentais dessas mobilizações, enxergavam como horizonte um modelo de educação/formação que incluíssem os professores nos processos de formulação do currículo de formação docente.

$\mathrm{Na}$ mesma perspectiva, retomamos o diálogo sobre a educação do campo, no Brasil e no Espírito Santo, teve como protagonistas a Igreja Católica, os movimentos sociais do campo e educadores/as do campo.

Assim, buscamos antes compreender a educação do campo por meio de seu contexto de lutas por uma educação crítica e libertadora que respeita as diversidades sociocultural dos sujeitos de direitos residentes no campo no Estado do Espírito Santo, assim como em outros Estados brasileiros.

Para contextualizar a história da Educação do Campo, evidenciamos alguns atos concretos de um processo de anos de lutas pela educação do campo. Nessa perspectiva, destacamos a $1^{\text {a }}$ Conferência Nacional de Educação do Campo em 1998, a $2^{a}$ Conferência Nacional de Educação do Campo em 2004. Ressaltamos também, um importante marco para a Educação do Campo a aprovação das Diretrizes Operacionais para a Educação Básica das Escolas do Campo em 2002.

Nesse movimento de lutas e conquista da educação do campo, outras demandas foram surgindo. Dentre elas, estão a formação de professores que 
considera e respeita a cultura dos sujeitos do campo, os saberes dos professores e sua trajetória pessoal e profissional.

Os professores detêm saberes específicos da profissão docente, saberes adquiridos na sua formação inicial universitária que são aplicados em diversas situações de sua prática profissional. Esses saberes profissionais são próprios da docência que vem se tornando mais reflexivo no ensino e na aprendizagem.

Pesquisas brasileiras relacionadas a formação de professores e saberes docentes vem crescendo. A partir da década de 1980, fez surgir diversas pesquisas no mundo, mais recentemente na Europa (TARDIF, 2002. p. 10). Para conversarmos sobre essa temática, buscamos embasamento teórico com os autores Maurice Tardif e Clermont Gauthier, ambos contribuíram em pesquisas no campo da formação de professores e saberes docentes.

Além dos autores Tardif (2002) e Gauthier e outros (2013), embasamos também em Arroyo (2011) e Caldart (2002), esses autores apresentam importantes contribuições acerca da formação docente, preconizam que existem na própria formação de professores acúmulo de história, vivencia e diálogo com diferentes saberes. Do mesmo modo, para conceituar os Temas Geradores e a constituição destes, Freire (1987) e Silva (2007) reverberam reflexões que apontam como o processo de investigação dos Temas Geradores são relevantes para identificar determinados problemas a partir da realidade concreta de grupos e ou comunidades.

\section{Educação do campo: contextualização histórica, sua expansão e rupturas}

No que se refere à formação de professores permite nos verificar as singularidades existentes entre os sujeitos que participam de um processo de formação. Compreendemos que cada professor tem o seu jeito, forma de mediar o conhecimento, pois, o modo de agir do docente se distancia substancialmente de toda forma de padronização. Nesse sentido, é necessário reafirmar qual o professor que pretendemos formar.

Diferente das perspectivas padronizadas que visam criar modelos únicos de ação, como a cultura do apostilamento, pretendemos discutir concepções de formação docente que considerem os sujeitos como autores dos seus processos 
formativos, colocando em destaque os processos de formação e a contextualização histórica da Educação do Campo, percebendo os elemento que configuram as transformações, as rupturas e quais reflexões foram evidenciadas nesse processo.

Desse modo, os caminhos percorridos, as vivências cotidianas e coletivas das experiências singulares, transfiguram-se e partem das ideias delineadas aqui, visa evidenciar a contextualização histórica da Educação do Campo no Brasil e Espírito Santo, com recorte da região norte do Estado, de modo, a abordar a expansão das escolas do ${ }^{1}$ e no campo e a formação de professores na perspectiva da construção dos saberes.

Nesse contexto histórico, o modelo de educação do campo tem suas origens na França, a primeira Maison Familiale ou Escola da Família Agrícola nasceu em 21 de novembro de 1935, na ocasião pelo Padre Granereau que observou por parte do Estado e da Igreja o desinteresse aos problemas do campo que estavam intimamente ligados a educação, (NOSELLA,2012. p. 45).

Nesse diálogo, a educação do campo alicerçada na Pedagogia da Alternância, surgiu no Brasil e no Espírito Santo no início de 1968 com a colaboração de Padre Humberto Pietrogrande, constituindo na ocasião, o Movimento de Educação Promocional do Espírito Santo (MEPES), entidade responsável pelas Escolas da Família Agrícola.

Com a abertura das escolas e perspectiva de expansão, logo, foi pensado na possibilidade da evasão dos alunos, com isso, surge a necessidade de criação do Centro de Formação em Pedagogia da Alternância para atuar com múltiplas funções, além de formar professores.

O Centro de Formação e reflexão, que, nas intenções da Entidade devia ser um centro plurivalente, de formação variada e de verdadeira pesquisa (Reflexão), acabou sendo única e exclusivamente um Centro de Formação de

\footnotetext{
1 Escolas no campo: Escolas localizadas no campo, porém não trabalham com a proposta metodológica e pedagógica da Pedagogia da Alternância.

Escolas do campo: conceito de Escolas localizadas no campo e adotam a proposta metodológica e pedagógica da Pedagogia da Alternância, consideração a identidade sociocultural dos sujeitos residentes no campo.
} 
Professores/Monitores das Escolas da Família Agrícola. (NOSELLA, 2012. p. 65).

O Centro de Formação de em Pedagogia da Alternância foi criado com objetivo de várias funções ou utilidades. Portanto, se tornou exclusivamente um Centro de Formação de Professores em Pedagogia da Alternância, o qual surgiu da necessidade de formar professores para atuar nas Escolas Família Agrícola.

Cabe informar, que o primeiro Centro de Formação em Pedagogia da Alternância constituído foi na Itália. Do ponto de vista prático e pedagógico, sobretudo, da expansão das EFAs no Espírito Santo, criou-se também o Centro de Formação em Pedagogia da Alternância no município de Anchieta, Estado do Espírito Santo.

De acordo com Nosella (2012), após a criação do Centro de Formação em Pedagogia de Alternância, inicia-se em 1971 a primeira turma do curso, chegando em 1976 com um total de realização de seis cursos de Formação em Pedagogia da Alternância, preconizando assim, a formação e qualificação de professores para atuar nas Escolas da Família Agrícola no Estado. Assim, compreendemos que o sentido da criação do Centro de Formação em Pedagogia da Alternância foi o seguinte:

[...] tentativa de racionalizar a experiência, tentativa de mediação entre um objetivo geral (promoção do homem do campo capixaba) e um instrumento técnico de aplicação desse objetivo (a Escola da Família Agrícola), que nascera e se estruturara fora do Brasil. (NOSELLA, 2012.p. 70).

Nessa perspectiva, o Centro de Formação em Pedagogia da Alternância pretendeu tornar mais reflexiva a experiência de formação, promovendo os sujeitos do campo por meio de instrumentos apropriados a proposta pedagógica das Escolas da Família Agrícola originara da França e que se estendeu para a região Norte do Estado.

Por meio do movimento da Pastoral Diocesana de São Mateus, iniciou a expansão das Escolas-Família para a região Norte do Estado do Espírito Santo. Em 1972, inauguram as Escolas Família de Jaguaré, na época pertencente ao município de São Mateus, São Gabriel da Palha e São Mateus. Posterior a esse 
período, vieram as Escolas Família de Montanha, Boa Esperança, Pinheiros, Rio Bananal, Marilândia, Nova Venécia, não necessariamente nessa ordem.

Com a expansão das Escolas Família Agrícola da região Sul para a região Norte do Estado, começa a surgir demandas específicas das escolas da região Norte, uma delas é a participação das famílias, professores e alunos nos processos decisórios necessários a dinâmica das escolas. Sendo assim, por meio de reuniões e assembleias foram constituindo as Associações das Escolas Família Agrícola da região Norte do Estado.

Com a criação das Associações das Escolas Família Agrícola era notório o movimento de rupturas, as famílias, alunos e professores buscavam a sua inserção nos processos decisórios do projeto educativo das EFAs.

Segundo Nosella (2012) outras escolas que trabalham com a Pedagogia da Alternância também foram surgindo no Norte do Estado, a exemplo, as Escolas Rurais Comunitárias - ECORMs, o qual dois municípios foram os pioneiros, Barra de São Francisco e Jaguaré. Com a criação das Escolas Comunitárias, o MEPES não dava suporte técnico, pedagógico e financeiro para essa nova proposta de Educação do Campo, especificamente constituído na região Norte do Estado.

Nos estudos de Nosella (2012), analisamos que a relação das rupturas estava ligada ao catolicismo do MEPES, haja visto, que a criação das EFAs na França e no Brasil se deu por meio da participação efetiva dos padres, conforme já mencionado, e com a expansão das EFAs e a criação das ECORMs no Norte do Estado, outros movimentos foram incorporados, como o Movimento de Pequenos Agricultores (MPA). Assim, outras dinâmicas foram se constituindo na Pedagogia da Alternância.

Diante disso, foram se construindo novas propostas da Pedagogia da Alternância com a participação efetiva de seus pares. A partir desse movimento articulatório, no dia 22 de abril de 2003, na Escola Família Agrícola de Marilândia é realizada a Assembleia de Fundação do Regional das Associações dos Centros Familiares de Formação em Alternância do Espírito Santo RACEFFAES, (RODRIGUES, 2019. p. 163). 
Neste processo de expansão, outras escolas foram constituídas com a mesma proposta da Pedagogia da Alternância, destaca-se, as Escolas de Assentamento da Reforma Agrária, fruto de lutas e conquistas do Movimento dos Trabalhadores Sem Terra (MST), que contou com apoio da Escola Família de Jaguaré na construção das propostas pedagógicas a serem implementadas pelas Escolas de Assentamentos ligadas ao Movimento dos Trabalhadores Sem Terra.

Nessa perspectiva, outro movimento que luta pela educação de seus pares é o Movimento Quilombola, embora, pouco tem se avançado na concretude da materialidade das Escolas Quilombolas no território Sapê do Norte, que compreendem os municípios de São Mateus e Conceição da Barra, território o qual está concentrado o maior número de comunidades quilombolas do Estado do Espírito Santo.

Todavia, esse contexto histórico da Educação do Campo do Brasil e do Espírito Santo, dispõem de compreendemos que a memória é um exercício político atual, individual e coletivo, e que por meio de dinâmicas problematizadoras, recoloca-se nas suas possibilidades permanentes de transformação" (LOCATELLI, 2012, p.35).

Dado o contexto da Educação do Campo, enfatiza que nesse processo sempre esteve pautado a formação de professores, desde a implantação das primeiras Escolas Famílias, onde surgiu a necessidade da criação do Centro de Formação de Professores em Pedagogia da Alternância, bem como, as parcerias com instituições públicas de Ensino Superior (Universidades Federais).

Em relação a Educação do Campo, destacamos como uma necessidade surgida pelos agricultores na França, experiência que se expandiu no Brasil e no Espírito Santo e na região Norte do Estado. É um modelo de educação que está sempre em movimento aproximando o ensino com a realidade dos alunos e comunidade.

Como propósito de fortalecimento da Educação do Campo, foi necessário pensar na formação dos professores. Com isso, buscou constituir um processo de formação de professores em Pedagogia da Alternância. 
Para tanto, compreendemos a importância das parcerias com alguns órgãos públicos e organizações sociais. As parcerias se deram com as Secretarias Municipais de Educação, com Universidade Federal do Espírito Santo, Movimento Educacional e Promocional do Espírito Santo, Regional das Associações dos Centros Familiares de Formação em Alternância do Espírito Santo, Setor de Educação do Campo do Movimento dos Trabalhadores Rurais Sem Terra (MST), além das formações internas que acontecem nas escolas de Pedagogia da Alternância e escolas multisseriadas.

\section{Os saberes docentes na perspectiva da educação do campo: um estudo a partir de Tardif (2002) e Gauthier (2013):}

Dado o contexto educacional e social do Brasil e também pelo legado histórico da profissão docente é imposta à prática educativa um número de demandas muito grande, levando assim o educador do século XXI a repensar a sua atuação em sala de aula e os enormes desafios profissionais que enfrenta para atender as exigências do contexto atual.

Nesse sentido, a profissão docente e a formação de professores a partir da década de 1980 começa a ser potencializada, ampliando espaços de debates, percebendo o ensino e o seu valor necessário a organização do trabalho. Conforme preconiza Tardif (2002).

As pessoas se interrogam cada vez mais sobre o valor do ensino e seus resultados. Enquanto as reformas anteriores enfatizavam muito mais as questões de sistema ou organização curricular, constata-se que atualmente, uma ênfase maior na profissão docente, e também na formação de professores e na organização do trabalho cotidiano. (TARDIF, 2002. p. 114).

De acordo com o autor, o ensino começa a ser pensado visando a aprendizagem dos alunos, que vai além da organização curricular. Essa reflexão perpassa pela formação dos professores, sobretudo, em sua prática docente vivenciada no cotidiano escolar, da sala de aula e na comunidade.

A formação de professores da Educação de Campo tem se reinventado no sentido de aproximar os conteúdos curriculares associando as especificidades do campo utilizando de práticas e técnicas, de recursos pedagógicos e didáticos de acordo com a realidade e contexto social e cultural 
dos sujeitos de direitos residentes no campo, considerando o seu modo de vida, de lidar com a terra, com a sua cultura e o cuidado com o meio ambiente.

[...] ensinar é utilizar, forçosamente, uma certa tecnologia, no sentido lato do termo. A pedagogia corresponde, na nossa opinião, a dimensão instrumental do ensino: ela é a prática concreta, esta prática que está sempre situada num ambiente de trabalho, que consiste em coordenar diferentes meios para produzir resultados educativos, isto é, socializar e instruir os alunos em interação com eles. No interior de um determinado contexto, tendo em vista atingir determinados objetivos, finalidades, em suma, determinados resultados. (TARDIF, 2002. p. 118).

De acordo com o autor, independente de qual for o trabalho, pressupõese a existência de um conjunto de tecnologia e teoria, conforme Freire (1987), não há trabalho sem técnica, tão pouco, objeto do trabalho sem relação do trabalhador com este objeto. A tecnicidade é, portanto, inerente ao trabalho, relacionando com a proposta pedagogia da Pedagogia da Alternância que em seu cotidiano busca a interação dos professores com os alunos com base no contexto social onde vivem.

Contudo, o ensino e a aprendizagem não podem ser compostos somente por técnicas e teorias, é preciso relacioná-las com as condições de um determinado contexto sociocultural, o qual é defendida na proposta metodológica e pedagógica da Pedagogia da Alternância materializada em seu Plano de Ensino.

As técnicas, as teorias, os instrumentos pedagógicos, os símbolos não podem ser considerados apenas como uma maquinaria, conforme define Tardif (2002) sobre a forma de utilização de técnicas materiais utilizadas no processo de ensino e aprendizagem.

[...] a pedagogia não se confunde, de forma alguma, com a "maquinaria", isto é, com as técnicas materiais (vídeos, filmes, computadores, etc.). Também não se confunde com as técnicas específicas com as quais é tão frequentemente identificada: aulas expositivas, o estudo dirigido, procedimento de ensinoaprendizagem socioindividualizantes, procedimentos de ensinoaprendizagem socializantes. (TARDIF, 2002. p. 119).

O autor pressupõe considerar que essas técnicas são partes ou elementos do ensino, não o todo. Para Tardif (2002), a pedagogia é muito mais 
uma tecnologia imaterial, intangível, ou seja, que não pode ser tocada, que diz respeito sobre as coisas como a transposição didática, a gestão da matéria, o conhecimento da matéria e conhecimento pedagógico da matéria, a gestão da classe, a motivação dos alunos, a relação professor-aluno-comunidade.

$\mathrm{Na}$ educação do campo, essa proposta de ensino socializantes, motivação dos alunos, relação professor-aluno-comunidade se concretiza por meio dos temas geradores, que tem como elemento principal, o diálogo com o plano de estudo que funciona como fio condutor da aprendizagem, da Integração das áreas de conhecimentos e dos conteúdos vivenciados por meio de pesquisa na comunidade, das contradições e compreensão da realidade onde vive e relaciona os problemas locais com os problemas global.

Nessa perspectiva, Foerste (2004), evidencia que a educação do campo é uma construção coletiva como prática de diálogo libertador, em cujo processo alunos e professores constroem-se e são construídos pelo movimento, como sujeitos históricos autônomos e capazes de ler o mundo. Além disso, interpreta a realidade a partir das contradições das relações do homem com a natureza e dos seres humanos, nas produções de materiais e simbólicos de existência.

No processo de aproximação dos sujeitos com a sua realidade, Tardif (2002), preconiza que alguns estudos dedicados a pedagogia e a disciplina, mostram que o professor em sua ação concreta da sala de aula, constrói estratégias, técnicas, esquemas, símbolos, para transformar a disciplina em função condicionante como o tempo, da avaliação, da motivação dos alunos, e para isso, utiliza-se alguns saberes, ora próprio da docência, ora de saberes constituídos em outros espaços e tempos fora das instituições de ensino.

Diante disso, considera-se os saberes próprios da profissão docente como um elemento essencial ao exercício do professor em sala de aula, porém, "os saberes da docência e os próprios docentes-trabalhadores têm estado ausentes nos conhecimentos escolares" (ARROYO, 2011, p. 71), compreende que essa ausência é consequência dos moldes da formação de professores que não consideram a sua vivência cotidiana da sala de aula nos processos formativos, tão pouco na constituições de alguns saberes . 
Os professores tem um acúmulo de saberes, tantas histórias e narrativas de vida da sua infância a fase adulta, e nesse processo de vivência vão se construindo novos fazeres e saberes por meio de conhecimento mútuo nas relações de convívio nas escolas e nas salas de aulas. De acordo com Arroyo (2011), será uma forma de conhecer a docência real, o trabalho real.

Tardif (2002) e Arroyo (2011) evidenciam que os saberes dos professores não são considerados na elaboração dos currículos e nas disciplinas, embora, são os professores responsáveis para colocá-los em prática na sala de aula.

[...] os currículos, as disciplinas são pensados como espaço de saberes, descolados dos sujeitos humanos produtores dessas vivências sociais e de conhecimento [...] ensinados e aprendidos sem referências aos sujeitos, contexto e experiências concretas. (ARROYO. p. 77).

Conforme o autor, os saberes curriculares e disciplinares não são elaborados por aqueles sujeitos produtores de vivência concreta, que na sua essência carrega experiências de contextos sociais que corroboram na transformação e desenvolvimento dos conteúdos ensinados e apreendidos na sala de aula.

Nessa mesma proposta, (TARDIF, 2002. p. 120) complementa que "o conteúdo ensinado na sala de aula nunca é transmitido simplesmente tal e qual", pois é necessário transformá-lo e adaptá-lo em função da compreensão de um determinado grupo de alunos e do contexto sócio cultural que o compõem. Assim, compreendemos a relação do autor com a proposta pedagógica da Educação do Campo no desenvolvimento dos conteúdos considerando a realidade sociocultural, ambiental e do seu modo de vida.

Todavia, as escolas que adotam a Pedagogia da Alternância buscam dentre outros fatores, aproximar alunos, comunidade e professores e têm como princípios, desenvolver uma metodologia que contemple as diferenças para propiciar a formação integral, tanto dos sujeitos quanto do meio onde vivem.

Nessa perspectiva, a Pedagogia da Alternância surgida na França pela União Nacional das Maisons Familiales Rurales, estabelece critérios orientadores de um Centro de Formação Familiar em Alternância - CEFFA, na intenção de uma formação baseada no desenvolvimento do campo, na ação 
específica do contexto do campo, na interação das famílias para com a associação, na metodologia pedagógica da alternância capaz de conduzir o conjunto (GIMONET, 2007).

Portanto, questões relacionadas ao contexto social e cultural dos sujeitos devem ser consideradas nas formações de professores. Mostra-se necessário que as formações sejam construídas com os professores, considerando, a sua experiência profissional, que se constrói a partir de significados sociais da profissão, de sua história de vida, de suas representações, de seus saberes, de suas angústias e anseios.

Além disso, Tardif (2002), enfatiza que os saberes profissionais dos professores são plurais, pois, carrega em seu próprio exercício do trabalho, conhecimentos e manifestações do saber-fazer diversificado e adquiridos por diversas fontes, ou seja, na sua trajetória pessoal e profissional.

Esses saberes são produzidos pelos professores no âmbito de suas práticas diárias, portanto, os professores são mediadores da cultura dos saberes e recaem sobre eles a missão educativa da escola, (TARDIF, 2002. p. 228).

Em seu estudo, Tardif (2002), propõe identificar e classificar os saberes dos professores, considerando as fontes de aquisição desses saberes e seus modos de integração no trabalho docente, conforme descrito no quadro abaixo.

Quadro 1 - Os saberes dos professores

\begin{tabular}{|c|c|c|}
\hline $\begin{array}{ll}\text { Saberes } & \text { dos } \\
\text { professores. } & \end{array}$ & $\begin{array}{l}\text { Fontes sociais de } \\
\text { aquisição. }\end{array}$ & $\begin{array}{l}\text { Modos de integração no } \\
\text { trabalho docente }\end{array}$ \\
\hline $\begin{array}{l}\text { Saberes pessoais dos } \\
\text { Professores. }\end{array}$ & $\begin{array}{l}\text { A família, o ambiente de } \\
\text { vida, a educação no } \\
\text { sentido lato etc. }\end{array}$ & $\begin{array}{l}\text { Pela história de vida e } \\
\text { pela } \\
\text { socialização primária. }\end{array}$ \\
\hline $\begin{array}{l}\text { Saberes proveniente da } \\
\text { formação escolar } \\
\text { anterior. }\end{array}$ & $\begin{array}{l}\text { A escola primária e } \\
\text { secundária, os estudos } \\
\text { pós-secundário não } \\
\text { especializados, etc. }\end{array}$ & $\begin{array}{l}\text { Pela formação e pela } \\
\text { socialização. }\end{array}$ \\
\hline $\begin{array}{lr}\text { Saberes } & \text { provenientes } \\
\text { da } & \text { formação }\end{array}$ & $\begin{array}{l}\text { Os estabelecimentos de } \\
\text { formação de professores, }\end{array}$ & $\begin{array}{l}\text { Pela formação e pela } \\
\text { socialização } \\
\text { profissionais }\end{array}$ \\
\hline
\end{tabular}




\begin{tabular}{|c|c|c|}
\hline $\begin{array}{l}\text { profissional para } 0 \\
\text { magistério. }\end{array}$ & $\begin{array}{l}\text { os estágios, os cursos de } \\
\text { reciclagem, etc. }\end{array}$ & $\begin{array}{l}\text { instituições de formação } \\
\text { de professores. }\end{array}$ \\
\hline $\begin{array}{l}\text { Saberes provenientes } \\
\text { dos programas e livros } \\
\text { didáticos usado no } \\
\text { trabalho. }\end{array}$ & $\begin{array}{l}\text { A utilização das } \\
\text { ferramentas dos } \\
\text { professores: programas, } \\
\text { livros didáticos, cadernos } \\
\text { de exercícios, fichas, etc. }\end{array}$ & $\begin{array}{l}\text { Pela utilização das } \\
\text { "ferramentas" de } \\
\text { trabalho, sua adaptação } \\
\text { às tarefas. }\end{array}$ \\
\hline $\begin{array}{l}\text { Saberes provenientes } \\
\text { de sua própria } \\
\text { experiência } \\
\text { profissão, na sala de } \\
\text { aula e na própria } \\
\text { escola. }\end{array}$ & $\begin{array}{l}\text { A prática do ofício na } \\
\text { escola e na sala de aula, } \\
\text { a experiências dos pares, } \\
\text { etc. }\end{array}$ & $\begin{array}{l}\text { Pela prática do trabalho } \\
\text { e pela socialização } \\
\text { profissional. }\end{array}$ \\
\hline
\end{tabular}

(TARDIF, 2002. p 63)

Cabe salientar, que o autor coloca em evidência todos os saberes utilizados pelos professores no contexto de sua profissão e da sala de aula, porém, ressalva que a natureza social do saber profissional está longe de ser todos produzidos diretamente pelos professores.

Alguns desses saberes são adquiridos de forma externa ao ofício de ensinar, ou seja, são provenientes de lugares anteriores ao seu trabalho cotidiano. Há saberes que são adquiridos na família, na escola e de sua cultura pessoal, outros da universidade, de instituições ou estabelecimento de ensino e outros provenientes dos pares, dos cursos de reciclagem, conforme preconiza Tardif (2002).

Neste sentido, o saber profissional está, de um certo modo, na confluência entre várias fontes de saberes provenientes da história de vida individual, da sociedade, da instituição escolar, dos outros autores educativos, dos lugares de formação, etc. (TARDIF, 2002. p. 64).

Segundo o autor, os saberes mobilizados pelos professores advêm de diversas formas identitárias e que utiliza referenciais de espaços e tempos para legitimar as experiências vividas. 
Outro ponto importante, são as contribuições de Gauthier e outros (2013), que complementa as narrativas de Tardif (2002), sobre os saberes docentes.

[...] é muito mais pertinente conceber o ensino com a mobilização de vários saberes que formam uma espécie de reservatório no qual o professor se abastece para responder as exigências de sua situação concreta de ensino. (GAUTHIER et al, 2013. p. 28).

O autor, evidencia a existência de um reservatório de saberes no qual o professor se abastece para responde as necessidades cotidianas da sala de aula. Deste modo, a tarefa de ensinar não contribui para a formalização de um saber específico.

Além disso, os saberes necessários à docência podem ser considerados como saberes profissionais, que se constituem a partir do conjunto de saberes transmitidos pelas academias durante a formação inicial de professores.

[...] é muito mais pertinente conceber o ensino como a mobilização de vários saberes que formam uma espécie de reservatório no qual os professores se abastecem para responder as exigências específicas da sua situação concreta de ensino. (GAUTHIER et al, 2013.p.28).

De acordo com o estudo do autor, os professores em sua prática cotidiana recorrem aos saberes provenientes da profissão docente para solucionar problemas surgidos no cotidiano da sala de aula, o qual é destacado por Tardif (2002) e reafirmado por Gauthier e outros (2013), que são saberes constituídos de diversas fontes e que se complementam. De modo que, ao discorrer sobre os saberes docentes à luz de Gauthier (2013), observa-se o quadro abaixo:

Quadro 2 - 0 reservatório de sabres

\begin{tabular}{|c|c|c|c|c|c|}
\hline SABERES & SABERES & SABERES & SABERES & SABERES & SABERES \\
\hline $\begin{array}{l}\text { disciplinas } \\
\text { (A } \\
\text { matéria) }\end{array}$ & $\begin{array}{l}\text { curriculares } \\
\text { (O } \\
\text { programa) }\end{array}$ & $\begin{array}{l}\text { das } \\
\text { ciências } \\
\text { da } \\
\text { educação }\end{array}$ & $\begin{array}{l}\text { da tradição } \\
\text { pedagógica } \\
\text { (O uso) }\end{array}$ & $\begin{array}{l}\text { experienciais } \\
\text { (A } \\
\text { jurisprudência } \\
\text { particular) }\end{array}$ & $\begin{array}{l}\text { da ação } \\
\text { pedagógica } \\
\text { (O repertório } \\
\text { de } \\
\text { conhecimentos } \\
\text { do ensino ou a } \\
\text { jurisprudência } \\
\text { pública } \\
\text { validade) }\end{array}$ \\
\hline
\end{tabular}

(GAUTHIER et al, 2013. p. 29) 
No que refere a interpretação do autor, os saberes disciplinares são os saberes elaborados por cientistas e pesquisadores, reconhecidos e identificados como pertencentes aos diferentes campos do conhecimento. São saberes produzidos e acumulados pela sociedade ao longo da história da humanidade, são administrados pela comunidade científica e o acesso a eles deve ser possibilitado por meio das instituições educacionais.

Embora, os professores não sejam inseridos nos processos de elaboração dos saberes disciplinares, os mesmos, tem a função de extrair desses saberes aquilo que importa ser ensinado.

Na compreensão do autor, os saberes curriculares estão relacionados aos programas escolares (objetivos, conteúdos e métodos). Ainda que os professores não participam da elaboração dos programas escolares, o conhecimento deles compõem seus saberes e devem aprender e aplicar.

Sobre os saberes das Ciências da Educação, segundo Gauthier e outros (2013), se referem ao conjunto de saberes produzidos a respeito da escola, sua organização, seu funcionamento a respeito da própria profissão docente. Portanto, esses saberes são adquiridos pelos professores ao longo de sua formação profissional e diferenciam de outra pessoa que saiba apenas o que é uma escola. Em suma, é um saber profissional específico que não está diretamente ligado com a ação pedagógica, mas serve de pano de fundo para a sua categoria, socializados da mesma maneira.

No entanto, os saberes da tradição pedagógica, pontua Gauthier e outros (2013), são pertencentes ao reservatório de saberes da profissão docente. Esses saberes referem-se à interpretação que cada professor tem a respeito da escola. $\mathrm{O}$ autor enfatiza que a tradição pedagógica povoa não somente as recordações de infância, mas também uma boa parte do cotidiano das escolas atuais.

Outro ponto relevante, segundo Gauthier e outros (2013), são os saberes experienciais, que correspondem aos conhecimentos construídos pelos professores em um processo individual, por sua vez, aprender por meio de suas próprias experiências significa um momento particular, que não deixa de ser algo pessoal, sobretudo, privado. 
Embora, o professor viva experiências das quais tira proveito, tais experiências, permanecem confinadas no ambiente da sala de aula. $O$ autor faz uma crítica aos saberes experienciais, afirmando que o que o limita é exatamente o fato de que ele é feito de pressupostos e de argumentos que não são verificados por meios de métodos científicos.

Contudo, na visão de Tardif (2002), os saberes experienciais dos professores são resultados de um processo de construção individual, mas, ao mesmo tempo, são compartilhados e legitimados por meio de processos de socialização profissional. Com isso, a interação entre os professores desencadearia um processo de valorização e de reconhecimento desses saberes como saberes de uma classe e não de um profissional em específico.

Além disso, Guathier e outros (2013), salienta, que o saber experiencial dos professores a partir do momento em que se torna público e que é testado pelas pesquisas realizadas em sala de aula é o que possibilitaria a construção de uma teoria da pedagogia.

Desse maneira, considerando as concepções a respeito do saber docente, tanto Tardif (2002) e Gauthier e outros (2013), deixam claro a necessidade de questionamento sobre o que é o "saber", porém, não há uma resposta pronta para a indagação, propõem compreensão daquilo que são as interações entre saberes e ações concretas dos professores. Para os autores, tudo se torna saber, os hábitos, as emoções, a intuição, as maneiras de fazer, de ser, as opiniões, as ideologias, as regras, as normas, qualquer representação cotidiana.

Em suma, preocupados com uma formação que inclui os professores no processo de pesquisa e na elaboração de um repertório de conhecimentos específicos ao ensino, tanto Tardif (2002) quanto Gauthier e outros (2013), questionam-se, que os professores embora são responsáveis por aplicar alguns conhecimentos específico da profissão docente, estes, não participam do processo de sua elaboração. Além disso, evidencia outros saberes, não menos importantes, que os professores carregam com si, constituídos em sua trajetória pessoal e profissional. 
Assim, como o movimento da Educação do Campo, Tardif (2002 e Gauthier e outros (2013), destacam a importância da construção coletiva do conhecimento, aproximando alunos, professores e comunidade. E nesse processo, a formação de professores deve considerar saberes e fazeres dos sujeitos. Nessa mesma perspectiva, (ARROYO, 2011. p.87) preconiza que na história dos saberes aprendidos pela categoria docente merece um lugar central nos cursos de formação de professores.

\section{Tema gerador: como os sujeitos se formam nesse processo?}

É notório que uma educação crítica e libertadora o processo educativo perpassa pela construção coletiva, assim, evidencia as contradições dos problemas identificados por alunos e comunidades a partir de sua realidade e de um contexto sociocultural.

Nesse sentido, os Temas Geradores são construídos ou deveria ser coletivamente a partir de uma realidade, dialogando com os sujeitos (alunos, comunidade, professores), percebendo as contradições e os significados dos problemas locais e global de um determinado lugar.

Assim, o Plano de Fortalecimento da Educação do Campo (PLAFEC), instrumento constituído pela Secretaria Municipal de Educação do município de São Mateus, Estado do Espírito Santo, por meio do Setor de Educação do Campo, é composto de aspecto filosófico, pedagógico e político, sistematiza a dinâmica da alternância nas escolas multisseriada, nele, o Tema Gerador está definido como elemento fundamental da motivação e da investigação de uma pesquisa.

[...] os Temas Geradores são situações que emergem do diagnóstico, ou seja, situações de interesse e motivação das pessoas e da realidade de abrangência da escola. (PLAFEC, 2012. p. 25).

Os Temas Geradores definido no PLAFEC (2012), comunga com a mesma ideia de Silva (2007), quando enfatiza que os Temas Geradores surgem por meio do diagnóstico de determinadas situações, motivadas por pessoas dado os problemas de um contexto de uma comunidade, apreendendo a trama 
pedagógica que transforma educador e educando em sujeitos do processo educativo.

No entanto, o professor educador precisa ter consciência que o conhecimento é inacabado, que precisa estar num permanente processo de busca para intervir e transformar a realidade. Do mesmo modo, o diálogo deve ser o elo entre professor e aluno, exercitando a pedagogia da escuta.

Sendo assim, num processo de uma educação libertadora os processos são construídos de forma igualitária, coletivamente, conforme enfatiza Freire (2011) e Silva (2007), é escutando que aprendemos a falar com o outro.

Dotados de saberes diferentes, porém não inferiores ou superiores uns em relação aos outros. Se o ponto de partida da educação libertadora, fundada no diálogo, é a realidade concreta e esta, nas palavras de Paulo Freire, são os dados objetivos, mais a compreensão que os sujeitos têm dela, é preciso ouvir esses sujeitos. É preciso "organizar a escuta" das populações inseridas na realidade a ser transformada. A escuta, nos trará as "falas significativas" da população, explicitando suas contradições e, portanto, os "temas geradores" de diálogo. Assim, se não houver escuta, não haverá diálogo e nossa ação se dará sobre ou para e não com ela. Consequentemente não haverá libertação, nem transformação da realidade. (SILVA, 2007. p. 11).

A reflexão evidenciada pelo do autor, diz respeito aos Temas Geradores, que necessariamente tem que partir do diálogo e da escuta dos sujeitos que trarão falas significativas da sua realidade, caso contrário, não haverá transformação da realidade, ou seja, não foi realizado com os sujeitos, foram realizados para eles, assim, não haverá libertação, tão pouco transformação.

Quando discorremos sobre os Temas Geradores, estamos ao mesmo tempo relacionando-os com a proposta pedagógica da educação do campo e dos seus modos de fazer educação, construindo processos junto com os sujeitos, suas especificidades e contexto social, político e cultural. Conforme preconiza Cardart (2002).

As políticas educacionais brasileiras quando pensaram a especificidade da população trabalhadora do campo sempre o fizeram na perspectiva do "para"; nem "com" e muito menos "dos" trabalhadores (CALDART,2002. p. 72). 
Na perspectiva, de construir uma educação não para, mas com os sujeitos, refuta-se qualquer forma de hierarquia. Sendo assim, não pode haver hierarquia de saberes, os saberes entrelaçam no conjunto, a partir do diálogo problematizador, que vai mostrando a realidade com consciência crítica e transformadora.

Diante disso, os professores tem um papel fundamental, pois, serão interlocutores do diálogo, são pessoas que ensinam e aprendem e se formam uns com os outros, construindo e sistematizando conhecimentos, mediando relações que vão sendo estabelecidas na construção coletiva. Vão se constituindo sujeitos da sua autoformação e transformação em sua reelaboração de mundo, reorganiza a prática educativa de forma humanizadora.

[...] nessa dinâmica de reorientação da prática educativa popular como processo de formação permanente tanto dos educadores, quanto da comunidade, o objetivo de construir coletivamente ações humanizadoras, a partir da proposta freiriana, via temas geradores, é o de transformar um espaço / tempo social em uma comunidade pedagógica, unidade educacional crítica que reflete sua diversidade sociocultural. (SILVA, 2007. p. 23).

Nesse sentido, os professores formam-se permanentemente por meio de sua prática educativa e construção coletiva. Contudo, os Temas Geradores tem como principal função transformar espaço/tempo social e reconhecimento da diversidade sociocultural de uma comunidade.

Nessa perspectiva, a construção dos Temas Geradores se dá por meio de um processo dialético, diagnosticado na investigação com contradições de visão de mundo, elaborando assim, um contra-tema (antítese) problematizando as falas significativas reelaboradas na perspectiva de transformação para um novo conhecimento (síntese), assim, define Freire (1987).

A investigação dos "temas geradores" ou da temática significativa do povo, tendo como objetivo fundamental a captação dos seus temas básicos, só a partir de cujo conhecimento é possível a organização do conteúdo programático para qualquer ação com ele, se instaura como ponto de partida do processo da ação, como síntese cultural. Daí que não seja possível dividir, em dois, os momentos deste processo: o da investigação temática e o da ação como síntese cultural. (FREIRE, 1987. p. 113). 
Conforme Freire (1987), a elaboração dos Temas Geradores e a investigação fazem parte de um mesmo processo, diagnosticados na investigação que resulta na evidencia de problemas identificados por um determinado grupo ou comunidade dentro de contexto sociocultural, a partir daí, as ideias são reelaboradas e sistematizadas na perspectiva de transformação daquela realidade.

No que diz respeito aos Temas Geradores, Silva (2007), preconiza que um grupo que não expressa concretamente os temas geradores, sugere, ao contrário um tema trágico: o tema do silêncio, dessa forma, imobilizando a fala a respeito das impressões de sua realidade concreta, da visão do meio onde vive.

Sendo assim, procurar o tema gerador é procurar o pensamento do homem sobre a realidade (SILVA, 2007.p. 65), que parte do conhecimento das relações sociais e suas reflexões política, crítica e sociocultural da sua realidade.

Percebe-se que o objetivo da busca pelo Tema Gerador é no sentido de compreendê-lo, sobretudo, os motivos da busca por temáticas significativas dada uma

realidade o qual se referem uma comunidade ou um grupo social.

Para compreender o processo de elaboração dos temas geradores e suas contradições, tomamos como referência o modelo adotado pelo setor de educação do campo da Secretaria Municipal de Educação de São Mateus.

Para tanto, toma-se como referência a experiência do Plano de Fortalecimento da Educação do Campo (PLAFEC) que teve sua base de constituição, as experiências das Escolas Comunitárias dos municípios de Colatina e Jaguaré.

Segundo Francisco José Souza Rodrigues, professor, pedagogo e representante do Setor de Formação da Secretaria Municipal de Educação do Município de São Mateus, sempre foi uma preocupação do setor a formação dos professores. Dito isto, com a expansão das escolas que trabalham com a pedagogia da alternância o PLAFEC foi construído para melhorar o desempenho escolar nas escolas multisseriadas do campo.

$\mathrm{Na}$ concretude do processo de formação dos professores, determinado no PLAFEC, tem um período que os estudantes não vão para a escola, o qual 
podemos nomear com Tempo/Escola, Tempo/Comunidade, nesse período do tempo comunidade, os alunos são orientados elaborar e fazer a pesquisa na realidade com os Temas Geradores pré-estabelecidos. Anualmente são trabalhados três Temas Geradores, divididos e organizados por semestre $\left(1^{\circ}, 2^{\circ}\right.$ e $3^{\circ}$ ), no $1^{\circ}$ trimestre o Tema Gerador é a Família, no $2^{\circ}$ o tema gerador é Alimentação e no $3^{\circ}$ trimestre o Tema Gerador é Saúde.

Em média são realizadas seis estadias letiva: três são para os alunos aplicar e desenvolver o plano de estudo e três para a atividade de retorno. Dessa forma, a estadia letiva dos alunos (Tempo comunidade) possibilita nesse período a formação dos professores. Essas formações acontecem nas microrregiões, ou formações locais, ou seja, na própria escola ou formação geral com todos os professores.

Essas formações só se tornaram possível pelo avanço que as escolas multisseriadas tiveram, a conquista dos pedagogos e diretores itinerantes, antes, esses trabalhavam na Secretaria de Educação e eram responsáveis por essas escolas, o trabalho dos diretores e pedagogos aconteciam de forma remota, ou seja, não estavam presentes no cotidiano dessas escolas, com isso, não conseguiam contemplar entre outros fatores, os processos de formação necessária.

Com a conquista das contratações dos pedagogos itinerantes, o setor de formação da Secretaria Municipal de Educação realiza a formação com os pedagogos, e a partir daí os pedagogos realizam a formação com os professores nas microrregiões ou na própria escola, considera-se esse processo como formação de formadores.

Essas formações tem como objetivo conhecer e compreender a função dos instrumentos pedagógico da educação do campo, a conjuntura do campo e a dinâmica das escolas multisseriadas, as formações acontecem de forma teórica e por meio de oficinas práticas, compartilhando saberes e experiências entre as escolas.

Retomando ao processo de constituição dos Temas Geradores, ao analisar o Plano de Curso tanto das escolas multisseriadas quanto das escolas comunitárias, observa-se que os Temas Geradores são comuns a todas as 
escolas, que vai desde a educação infantil até o $5^{\circ}$ ano. Conforme mencionado para as escolas multisseriadas os Temas Geradores definidos são: $1^{\circ}$ trimestre A Família, no $2^{\circ}$ trimestre Terra, no $3^{\circ}$ trimestre Saúde.

Na mesma dinâmica, as escolas de alternância os Temas Geradores definidos são: no $6^{\circ}$ ano os Temas Geradores são os mesmos temas das escolas multisseriadas, para $\circ 7^{\circ}$ ano os TGs são: Os Meios de Comunicação e Transporte, o Clima e o Trabalho e Energia, o $8^{\circ}$ ano os temas geradores são: Reprodução, As Atividade Econômicas Regionais e Culturas e Criações, o $9^{\circ}$ ano os temas são: As Atividades Socioeconômicas Regionais, Culturas e Criações e Organizações Sociais

Contudo, observa-se que a metodologia utilizada para constituir os temas geradores vai na contramão do que afirma Freire (1987), " Investigar o tema gerador é investigar, repitamos, o pensar dos homens referido à realidade, é investigar seu atuar sobre a realidade, que é sua práxis (FREIRE, 1987. p. 63), também não está explícito no documento analisado quais foram os critérios ou justificativa para definição dos temas geradores, visto que as escolas estão localizadas em regiões diferentes, com públicos diferentes.

Com isso, recorremos a Freire (1987), pois, quanto mais assumam os homens uma postura ativa na investigação de sua temática, tanto mais aprofundam a sua tomada de consciência em torno da realidade (FREIRE, 1987. p. 63). Dessa forma, indaga se as temáticas são significativas paras alunos, professores e comunidade? Se nesse processo os temas geradores limitam ou ampliam a formação dos professores? São questões problematizadoras que precisam ser aprofundadas em outro momento. Enfatiza-se que essas questões foram expostas no sentido da reflexão para a educação do campo como um processo inacabado e que está em constante construção e transformação.

Constata-se, não ser possível a apropriação dos sujeitos em relação as temáticas, isso revela que os Temas Geradores não foram constituídos em sua pureza objetiva, tão pouco, aprofundam a tomada de consciência da sua realidade.

O Tema Gerador tem que ser o ponto de partida para a prática educacional que direciona a prática educativa, pois, procurar o Tema Gerador é 
procurar o pensamento do homem sobre a realidade (SILVA, 2007. p. 65). Se não acontece o exercício da busca dos Temas Geradores pelos sujeitos, compreende-se que os Temas Geradores não foram criados por eles e sim para eles, que podem ocasionar na não transformação da realidade o qual alunos, professores e comunidades estão inseridos.

\section{Processo de constituição das escolas comunitárias em pedagogia da alternãncia}

Em 2011 iniciou a discussão do projeto das escolas comunitárias, feito com a participação dos agricultores e famílias da região do Córrego Seco, por ter uma base do Movimento dos Pequenos Agricultores (MPA) e famílias que conheciam as escolas em alternância, iniciado esse processo de implantação de uma escola em alternância, assim, em 2012 foi criada a Escola Comunitária em Pedagogia da Alternância na comunidade Córrego Seco, região de Nestor Gomes em São Mateus.

Na região do Nativo, já existia uma escola de Ensino Infantil e Ensino Fundamental, porém, algumas famílias daquela região tinham o desejo e necessidade de ter uma escola família. Em 2012 iniciou um processo de discussão sobre a adaptação da escola para escola em alternância. Assim, surge então, a Escola Comunitária Maria Francisca Nunes Coutinho.

Da mesma forma, foi a discussão da proposta da escola do Assentamento Zumbi dos Palmares, no assentamento existia uma escola que em determinado momento quase fechou porque o município de Nova Venécia passava com o transporte escolar dentro do assentamento e levava os estudantes para Nova Venécia. A partir dessa problemática as famílias assentadas se mobilizaram juntamente com o (MST), o setor de educação, equipe de professores, diretor e lideranças do assentamento. Com isso, a antiga escola passou por uma adaptação e logo depois a construção de uma nova escola que utiliza a Pedagogia da Alternância.

Ademais, esse movimento e articulação da Educação do Campo no município de São Mateus resultou na criação do setor de Educação do Campo na Secretaria de Municipal de Educação, como já mencionado existia um setor 
de formação, junto a esse, também ficou a Educação do Campo, esse setor é o responsável pela formação de professores das escolas multisseriadas.

Constatou-se que não adianta ter um projeto pedagógico que tem uma dinâmica, uma filosofia com uma perspectiva de formação pedagógica, política e filosófica e não preparar os professores para esse projeto.

Em relação aos educadores das escolas comunitárias o setor de formação em parceria com a RACCEFFAES articula e organiza as formações dos professores. A RACCEFFAES tem dois programas de formação organizado em módulos: a formação básica, que é para aqueles professores que chegam nas escolas em alternância sem nenhum conhecimento da proposta metodológica e pedagógica da Pedagogia da Alternância; a formação Inicial que é mais extenso, organizado em seis módulos de formação mais densa e o outro programa de formações regionais que é uma formação com todos os educadores das escolas em alternância do Norte do Estado que tem relação com a RACCEFFAES.

Todavia, a Escola do Zumbi dos Palmares que é uma escola de assentamento e tem uma relação com o setor de Educação do Movimento dos Trabalhadores Sem Terra (MST), o setor de formação orienta e organiza os professores a participar da formação dada pelo setor de Educação do MST.

Além disso, para essas escolas de alternância o setor de formação faz acompanhamento pedagógico e formações específicas. Têm-se um planejamento de acompanhamento discutido com os diretores e pedagogos dessas escolas. O setor de educação dialoga com os diretores e pedagogos que apresentam demandas de temáticas de formação, além, da autonomia das escolas em realizar as suas próprias formações no planejamento coletivo.

O setor de formação avalia que as formações tem contribuído com o melhoramento da proposta pedagógica, avançando no desenvolvimento dos instrumentos pedagógicos das escolas comunitárias, outro avanço significativo é na aplicabilidade da proposta pedagógica nas escolas multisseriadas. Contudo, avalia que há um grande desafio a ser superado, devido a maioria dos professores serem Designação Temporária (DTs), ocorrem uma rotatividade constantes de professores nas escolas multisseriadas, o que exigem está sempre dando formação inicial. 


\section{Considerações finais}

Eleva-se a importância das pesquisas relacionadas ao ensino, sobretudo, dos programas de formação de professores como um processo deliberativo e político que privilegia alguns valores dos sujeitos envolvidos.

A pesquisa pode contribuir na compreensão e avaliação da realidade, com apontamentos de mudanças e transformações necessárias ao ensino, destacando a importância da formação de professores diante de seus desafios cotidiano.

Pode-se afirmar que o processo que torna um professor o que ele é e que permite a aquisição e a construção dos saberes necessários à sua prática profissional é complexo e marcado por diferentes períodos, diferentes vivências e experiências.

Os cursos de formação inicial, se tomarmos como base a obra desses autores, não são, portanto, as únicas fontes de saberes dos professores. Ficou compreendido que a prática profissional de um docente é resultado da relação existente entre os seus diferentes saberes, adquiridos não somente na sua preparação profissional, cursada em instituições destinadas à formação de professores.

Os saberes dos professores são, da mesma forma, resultantes dos conhecimentos e ensinamentos aprendidos na sua vida familiar e social, no decorrer de sua trajetória escolar como aluno, no seu próprio lugar de trabalho, das relações estabelecidas com alunos e colegas de profissão.

Outro ponto a considerar é que na Educação do campo mesmo com as suas rupturas ela é um processo inacabado, que necessita reconsiderar alguns aspectos, sobretudo, o modo de constituição dos Temas Geradores, que é comum as Escolas Famílias, as Escolas de Assentamentos, Escolas Comunitárias e Escolas Multisseriadas, haja visto, que os alunos atendidos por essas instituições de ensino, são públicos distintos, assentados da reforma agrária, pequenos agricultores, quilombolas e pescadores que tem suas especificidades no seu modo vida e na sua cultura. Percebemos então, a contradição do próprio PLAFEC quando expõem o conceito de Temas Geradores e seu processo de constituição. Espera-se, que nesse movimento de 
reflexão essas questões sejam abordadas pelas organizações sociais, universidades, secretarias municipais de educação, professores, pedagogos, alunos, sobretudo, o setor de formação dessas instituições, retomar os conceitos e o processo de constituição dos Temas Geradores, se faz necessário quando pensamos em uma educação crítica e libertadora, constituída de diversas realidades e diferentes contextos sociais.

\section{Referencias}

ALVES, N.; Garcia, R. L. A construção do conhecimento e o currículo dos cursos de formação de professores na vivência de um processo. In: Alves, N. (Org.). Formação de professores: pensar e fazer. 6. ed. São Paulo: Cortez, 2001.

ARROYO, Miguel, G. Currículo, território em disputa. - ed. - Petrópolis, RJ: Vozes, 2013.

CALDART, R. S. (2002) Por uma Educação do Campo: traços de uma identidade em construção. In: Educação do Campo: identidade e políticas públicas. Kolling, E.J. et al. (orgs). Coleção Por uma Educação do Campo, n 4. Brasília: Art. Nacional Por Uma Educação do Campo. 25 - 36 p.

FOERSTE, Erineu. Discussões acerca do Projeto Político da Educação do Campo. Doc. 2004.

FREIRE, Paulo. Pedagogia do oprimido. 17ª ed. Rio de Janeiro, Paz e Terra, 1987.

GAUTHIER, Clermont (et. al), Tradução Francisco Pereira. Por uma teoria da pedagogia: pesquisas contemporâneas sobre o saber docente. $3^{a}$ dição. Unijuí, 2013.

GIMONET, Jean-Claude. Nascimento e desenvolvimento de um movimento educativo: as casas familiares rurais de educação e orientação. In: I Seminário internacional da pedagogia da alternância: alternância e desenvolvimento. Anais... Salvador: UNEFAB, 1999, p.39-48.

LOCATELLI, Andrea Brandão. Espaços e tempos de grupos escolares na cena republicana do início do século $X X$ : arquitetura, memórias e história. Tese (Doutorado em Educação) - Programa de Pós-Graduação em Educação. Universidade Federal do Espírito Santo, Vitória, 2012.

NOSELLA, Paolo. Educação do campo: origens da pedagogia da alternância no Brasil. Vitória: EDUFES, 2012.

RODRIGUES, Francisco, José, Souza. Rupturas e permanências no processo educativo dos centros familiares de formação em alternância - 
CEFFAS-ES: EXPANSÃO DA PEDAGOGIA DA ALTERNÂNCIA NO NORTE DO ESTADO DO ESPÍRITO SANTO. 2019. Dissertação (Mestrado em Educação) Programa de Pós-Graduação em Ensino na Educação Básica do Centro Universitário Norte do Espírito Santo, da Universidade Federal do Espírito Santo. São Mateus. 2019.

. Formação em Pedagogia da Alternância. Setor de formação - Secretaria municipal de Educação de São Mateus.2020.

SILVA, Antônio Fernando Gouvêa. A busca do tema gerador na práxis da educação popular- Curitiba: Editora - Gráfica Popular, 2007.

\section{Sobre as autoras}

\section{Sandra Madalena Valentim de Souza}

sandra.es.valentim@gmail.com

Técnica em Agropecuária (1994) pela Escola Família Agrícola de Boa Esperança/ES, Graduação em Licenciatura em Educação do Campo na área de Ciências Humanas (2018) pela Universidade Federal do Espírito Santo/UFES, Especialização em Educação do Campo e Gestão Educacional e Inspeção Escolar (2020) pela Faculdade ÚNICA DE IPATINGA/MG, Mestranda em Ensino e Educação Básica pela Universidade Federal do Espírito Santos/UFES. Professora, Pesquisa Formação de Professores na Educação do Campo.

\section{Andrea Brandão Locatelli}

andrea.locatelli@ufes.br

Graduação em Educação Física (1993), Mestrado (2007) e Doutorado (2012) em Educação pela Universidade Federal do Espírito Santo/UFES. Pesquisadora do Instituto de Pesquisa em Educação e Educação Física/Proteoria/UFES; e professora na Universidade Federal do Espírito Santo/UFES. Pesquisa sobre Formação de Professores, Ensino, Práticas pedagógicas e na área de História da Educação no Espírito Santo. 